
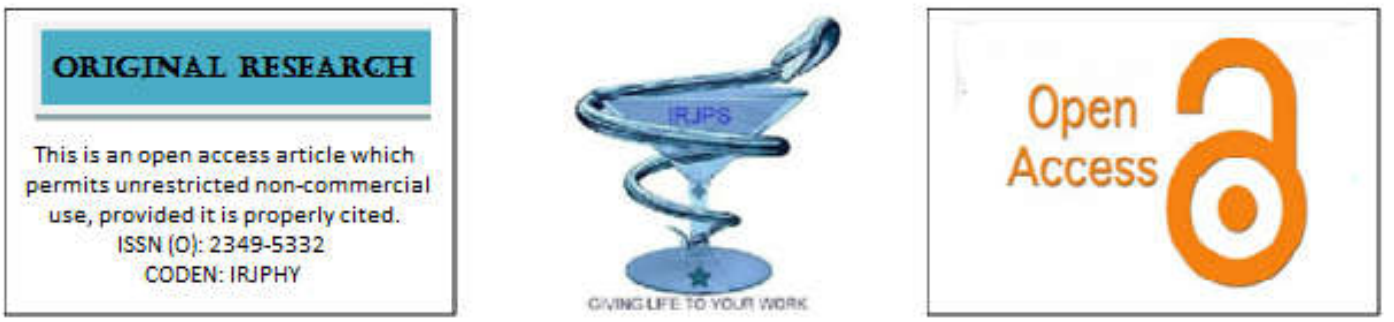

\title{
ANALYSIS OF LARGE DATA (FRANKFURT HOSPITAL) OF 2000 DIABETIC PATIENTS REVEALED HIGH INSULIN LEVEL S ASSOCIATED WITH INCREASED HYPERGLYCEMIC STATES
}

\author{
Ahed J Alkhatib ${ }^{1,2}$, Suha K. Ababneh ${ }^{3}$ \\ 1 Department of Legal Medicine, Toxicology of Forensic Medicine, School of Medicine, University of Science \\ and Technology, Jordan. \\ 2 International Mariinskaya Academy, Department of Medicine and Critical care, Department of Philosophy, \\ Academician secretary of Department of Sociology \\ 3 Ministry of Education, Jordan
}

Submitted on: 04.11.19;

Revised on: 18.11.19;

Accepted on: 22.11.19

\begin{abstract}
Diabetes remains one of the most prevalent diseases at global level. It affects people at various age groups. Although the definition of diabetes depends on the insulin in terms of concentration or function, assessment of diabetic is based on determining glucose level rather than insulin. The main objective of the present study was to analyze dataset regarding diabetes involving some basic diabetic parameters such as glucose and insulin. The methodology involves extracting data from online source (Kaggle) in which diabetic data of 2000 patients was shared from Frankfurt Hospital. Data was filtered to exclude the invalid cases. The remaining cases were 1035 participants. Data was analyzed at two stages, the first stage gave a general description of variables. To take a depth understanding of the data, data was further subdivided into diabetic and control groups according to glucose level. The relations between study groups were computed based on independent $\mathrm{T}$ test, and significance was considered at $\alpha \leq 0.05$. Study findings showed that glucose level of study participants was $120.89 \mathrm{mg} / \mathrm{dl} \pm 31.97 \mathrm{mg} / \mathrm{dl}$, insulin level was $79.80 \pm 115.22 \mathrm{ng} / \mathrm{ml}$, BMI was $31.99 \pm 7.88 \mathrm{~kg} / \mathrm{m}^{2}$, mean age of study participants was about $33.24 \pm 11.76$ years, the mean of diastolic blood pressure was $69.11 \pm 19.35 \mathrm{mmHg}$, and the mean of skin thickness was $20.54 \pm 15.95 \mathrm{~mm}$. in the second stage of analysis, significant differences $(p<0.05)$ were found between all variables including glucose level, skin thickness, BMI, and insulin level. No significant difference in mean level between study groups were found for diastolic blood pressure $(\mathrm{p}=0.072)$. Taken together, diabetic therapeutic approaches should be revised.
\end{abstract}

KEYWORDS: Diabetes, Glucose, Insulin, Datasets, Kaggle online source.

Corresponding author: Ahed J Alkhatib,

Mobile: +962795905145

E-mail: ajalkhatib@just.edu.jo
Indian Research Journal of Pharmacy and Science; 23(2019)2014-2018; Journal Home Page: https://www.irjps.in DOI: 10.21276/irjps.2019.6.4.2 


\section{INTRODUCTION:}

Diabetes as a disease mainly comprises two types known as: type 1 diabetes and type 2 diabetes. Both types are considered as diseases with great diversity leading to great variations in disease progression and outcomes. Although, determining the type of disease is important to set up therapeutic plan. Not all patients are likely to exactly be classified upon initiating of treatment ${ }^{1}$ (American Diabetes Association, 2019).

In type 1 and type 2 diabetes, different hereditary and natural variables can bring about the dynamic loss of b-cell mass as well as capacity that shows clinically as hyperglycemia. Once hyperglycemia happens, patients with all types of diabetes are in danger for building up the equivalent incessant inconveniences, in spite of the fact that paces of movement may vary. The distinguishing proof of individualized treatments for diabetes later on will require better portrayal of the numerous ways to bcell end or brokenness ${ }^{2}$.

The diagnosis of diabetes can be made dependent on plasma glucose criteria, either the fasting plasma glucose (FPG) level or the 2-h plasma glucose (2-h PG) level during a 75-g oral glucose resistance test (OGTT), or then again A1C criteria ${ }^{3}$. FPG, 2-h PG during 75-g OGTT, and A1C are similarly fitting for symptomatic testing. It ought to be noted that the tests don't really distinguish diabetes in similar people. The viability of intercessions for essential avoidance of type 2 diabetes has principally been exhibited among people who have disabled glucose resilience (IGT) with or without raised fasting glucose, not for people with disengaged weakened fasting glucose (IFG) or for those with prediabetes characterized by A1C criteria. Similar tests might be utilized to screen for and analyze diabetes and to recognize people with prediabetes. Diabetes might be distinguished anyplace along the range of clinical situations: in apparently generally safe people who happen to have glucose testing, in people tried in view of diabetes hazard appraisal, and in symptomatic patients ${ }^{4,5}$.

Some epidemiologic data regarding diabetes showed that ${ }^{6}$ : The total number of diabetic patients has increased overtime from 108 to 422 million from 1980 to 2014.
- At global level, the prevalence of diabetes increased from $4.7 \%$ to $8.5 \%$ during 1980 and 2014 among adults.

- The most increasing episodes of diabetes prevalence were shown in middle- and low-income countries.

- Diabetes is significantly associated with complications such as blindness, kidney failure, heart attacks, stroke and lower limb amputation.

\section{OBJECTIVES:}

The present study aimed to analyze large diabetic data taken from Frankfurt Hospital, Germany.

\section{METHODS AND SUBJECTS}

Study design: A retrospective study was conducted.

Data source: The data was obtained from online source $^{7}$. The Dataset of diabetes, taken from the hospital Frankfurt, Germany was analyzed in this study. The data consisted of 2000 female patients with diabetes.

Study variables: The following variables were included in this study: glucose, insulin, age, blood pressure, and skin thickness.

Study sample: Study sample included 2000 diabetic women. We have filtered data to be appropriate for this study. After that remaining data included 1035 participants.

Statistical analysis: The analysis of data was carried out using SPSS version 21. Data was presented as means and standard deviations in table formats and figures. The relationships between variables were determined based on independent $T$ test. Significance was considered at $\alpha \leq 0.05$.

\section{RESULTS}

As seen in table 1, glucose level of study participants was $120.89 \mathrm{mg} / \mathrm{dl} \pm 31.97 \mathrm{mg} / \mathrm{dl}$. Insulin level was $79.80 \pm 115.22 \mathrm{ng} / \mathrm{ml}$. BMI was $31.99 \pm 7.88 \mathrm{~kg} / \mathrm{m}^{2}$. The mean age of study participants was about $33.24 \pm 11.76$ years. The mean of diastolic blood pressure was $69.11 \pm 19.35$ $\mathrm{mmHg}$. The mean of skin thickness was $20.54 \pm 15.95 \mathrm{~mm}$. 
Table 1: Clinical characteristics of study participant

\begin{tabular}{|l|c|c|}
\hline \multicolumn{1}{|c|}{ Variable } & Mean $(\mathrm{M})$ & SD \\
\hline Glucose (mg/dl) & 120.89 & 31.97 \\
\hline Insulin (ng/ml) & 79.80 & 115.22 \\
\hline BMI (kg/m ${ }^{2}$ ) & 31.99 & 7.88 \\
\hline Age (years) & 33.24 & 11.76 \\
\hline Blood pressure (Diastolic $\mathbf{m m ~ H g ) ~}$ & 69.11 & 19.35 \\
\hline Skin thickness (mm) & 20.54 & 15.95 \\
\hline
\end{tabular}

As indicated in table 2, using independent $\mathrm{T}$ test, the mean differences between control group and diabetic group were computed. Significant differences $(\mathrm{p}<0.05)$ were found between all variables including glucose level, skin thickness,
BMI, and insulin level. No significant difference in mean level between study groups were found for diastolic blood pressure $(\mathrm{p}=0.072)$. As seen in figure 1, insulin level increased as glucose level increased in study groups.

Table 2: The relationship between study variables (control group V.S diabetic group) using independent T test

\begin{tabular}{|l|c|c|}
\hline \multicolumn{1}{|c|}{ Variables } & M $( \pm$ SD) & Significance \\
\hline Glucose -control & $\mathbf{1 0 9 . 9 8} \pm 26.14$ & $\mathbf{0 . 0 0 0}$ \\
Glucose-diabetes & $141.26 \pm 31.94$ & \\
\hline Blood pressure-control & $\mathbf{6 8 . 1 8} \pm \mathbf{1 8 . 3}$ & $\mathbf{0 . 0 7 2}$ \\
Blood pressure-diabetes & $\mathbf{7 0 . 8 2} \pm \mathbf{2 1 . 4 9}$ & \\
\hline Skin thickness-control & $\mathbf{1 9 . 6 6} \pm 14.89$ & $\mathbf{0 . 0 3 8}$ \\
Skin thickness-diabetes & $\mathbf{2 2 . 1 6} \pm 17.68$ & \\
\hline BMI-control & $\mathbf{3 0 . 3 4} \pm 7.69$ & $\mathbf{0 . 0 0 0}$ \\
BMI-diabetes & $\mathbf{3 5 . 1 4 3} \pm 7.26$ & \\
\hline Insulin -control & $\mathbf{6 8 . 7 9} \pm 98.87$ & $\mathbf{0 . 0 0 0}$ \\
Insulin-diabetes & $\mathbf{1 0 0 . 3 4} \pm 138.69$ & \\
\hline
\end{tabular}

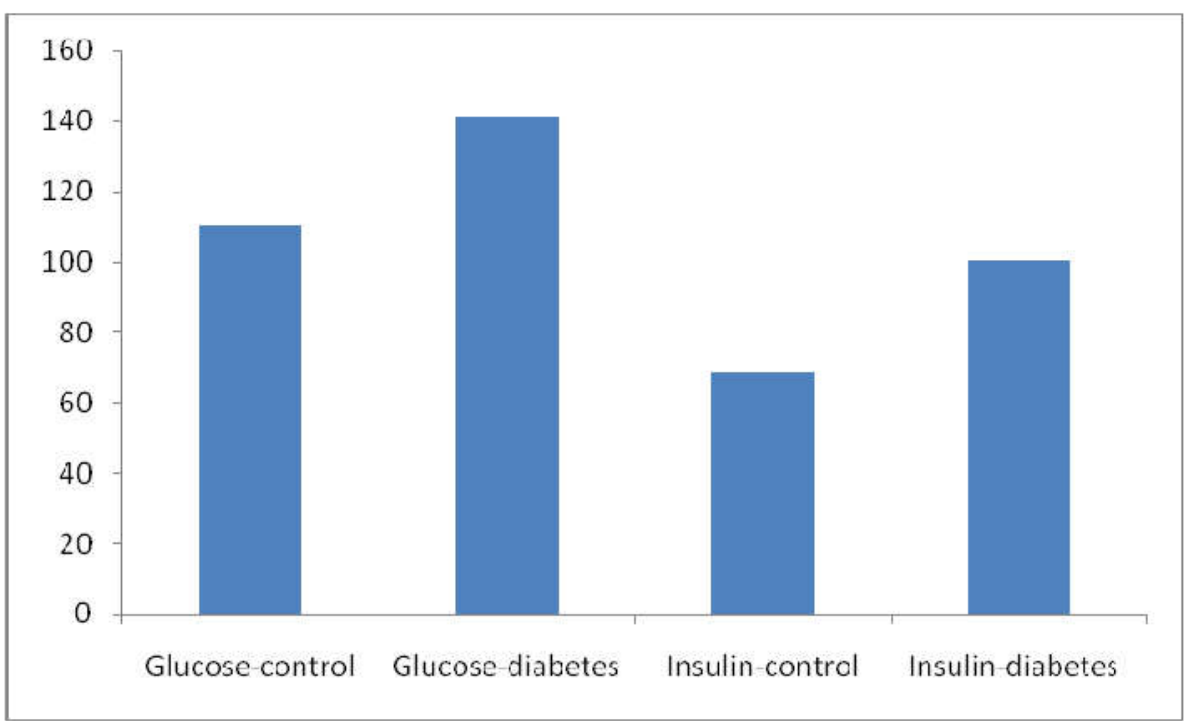

Figure 1: Mean levels of glucose and insulin in study groups. 


\section{DISCUSSION:}

The present study was conducted to continue our previous efforts in introducing new insights to diabetes including being more likely to be a neurological disease more than a metabolic disease $^{8}$. Although, diabetic studies count it within the context of metabolic syndrome, we showed that the possibility of having another neurologic disorder is plausible. We also previously showed that diabetes is associated changes with molecular alterations in white matter ${ }^{9}$. Accordingly, evidence has been accumulated to support our claims about diabetes development and pathogenesis. We also previously showed that there is a large possibility to have diabetes and diabetic complications as independent events through studying the axis between nervous system and other systems with the involvement of similar etiologies rather than depending on the other ${ }^{10}$.

In this study, we referred to a large data posted on Kaggle online source ${ }^{7}$. The Dataset of diabetes, taken from the hospital Frankfurt, Germany included 2000 patients.

It is worth to mention that the use of dataset requires the employment of some statistical arts and spirits to understand data. The first trial of data analysis showed that glucose level of study participants was $120.89 \mathrm{mg} / \mathrm{dl} \pm 31.97 \mathrm{mg} / \mathrm{dl}$. Insulin level was $79.80 \pm 115.22 \mathrm{ng} / \mathrm{ml}$. BMI was $31.99 \pm 7.88 \mathrm{~kg} / \mathrm{m}^{2}$. The mean age of study participants was about $33.24 \pm 11.76$ years. The mean of diastolic blood pressure was $69.11 \pm 19.35$ mmHg. The mean of skin thickness was $20.54 \pm 15.95 \mathrm{~mm}$. These figures pointed to a diabetic status or pre-diabetic status. To make a deep understanding of the data, we subdivided the participants into diabetic and control groups. Using independent $\mathrm{T}$ test, the mean differences between control group and diabetic group were computed. Significant differences $\quad(p<0.05)$ were found between all variables including glucose level, skin thickness, BMI, and insulin level. No significant difference in mean level between study groups were found for diastolic blood pressure $(\mathrm{p}=0.072)$.

It was worth mentioning that the ratio of mean glucose level in diabetic group/ mean glucose level in control group=141.26 mg/dl/109.98mg/dl=1.28.

On the other hand, the ratio of insulin level in diabetic group/ insulin level in control group=100.34 ng/ml/68.79ng/ml=1.46.

These results showed that insulin levels increase as the glucose levels increase. We have reached similar findings that are confirmed by the present results $^{11}$. Actually, there are two points to be taken into account, the first is about lacking clinical data regarding insulin, although the definition of diabetes rotated round the axis of insulin, and glucose is indirectly associated with the definition of diabetes. The second point is related to the rational of using treatment with insulin while it is already existing in more quantities than required.

\section{CONCLUSIONS:}

The present study showed that as diabetic status becomes more developed, both levels of glucose and insulin increased, and the ratio of increased insulin levels among diabetics compared with control group subjects is more than that for glucose levels in diabetic groups compared with that for control group subjects.

\section{REFERENCES:}

1- American Diabetes Association. 2. Classification and diagnosis of diabetes: Standards of Medical Care in Diabetesd2019. Diabetes Care 2019;42(Suppl. 1):S13-S28.

2- Skyler JS, Bakris GL, Bonifacio E, et al. Differentiation of diabetes by pathophysiology, natural history, and prognosis. Diabetes 2017;66:241- 255.

3- International Expert Committee. International Expert Committee report on the role of the $\mathrm{A} 1 \mathrm{C}$ assay in the diagnosis of diabetes. Diabetes Care 2009;32:1327-1334.

4- Knowler WC, Barrett-Connor E, Fowler SE, et al.; Diabetes Prevention Program Research Group. Reduction in the incidence of type 2 diabetes with lifestyle intervention or metformin. N Engl J Med 2002;346:393-403

5- Tuomilehto J, Lindstrom J, Eriksson JG, et al.; Finnish Diabetes Prevention Study Group. Prevention of type 2 diabetes mellitus by changes in lifestyle among subjects with impaired glucose tolerance. N Engl J Med 2001;344: 1343-1350.

6- https://www.who.int/news-room/factsheets/detail/diabetes, -retrieved on 15/11/2019.

7- https://www.kaggle.com/johndasilva/diabetes. 8- Ahed J Alkhatib. New Insights to Diabetes: Is Diabetes a Metabolic Disorder or a Neurological Disease? International Journal of Diabetes \& Metabolic Disorders, 2019; 4 (1):1-3.

9- Ahed Alkhatib. Co-expression of iNOS and HSP70 in diabetes type 1 makes a rational 
hypothesis to explain the diabetic neuropathy. European Scientific Journal, 2013; 9 (3), 145-156. 10- Ahed J Alkhatib. Diabetes and diabetic neuropathies are independent events: a new medical hypothesis. Ind Res J Pharm and Sci, 2017; 4 (3): 1064-1067.
11- Ahed J Alkhatib. New Insights of Diabetes: is it Rational to Initiate Insulin Treatment for Diabetes Type 2 Patients. Journal of Diabetes and Islet Biology, 2019; 2 (1): Doi: 10.31579/ 2641$8975 / 012$ 